Research Square
Preprints are preliminary reports that have not undergone peer review.

They should not be considered conclusive, used to inform clinical practice, or referenced by the media as validated information.

\title{
Efficacy and Safety of De-Escalation of Anti-Platelet Therapy after Percutaneous Coronary Intervention in Patients with Acute Coronary Syndrome: A Meta-Analysis of Randomized Clinical Trials
}

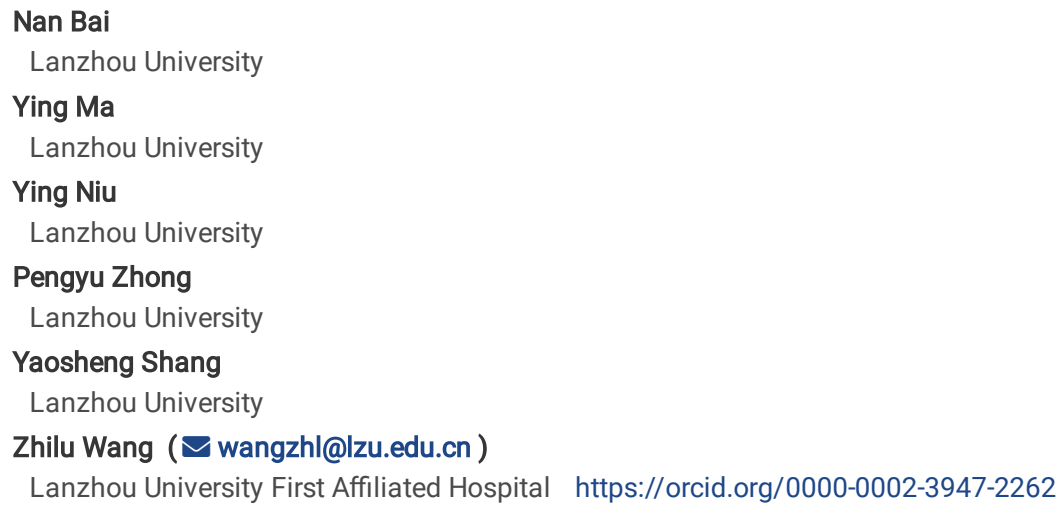




\section{Abstract}

Purpose: This meta-analysis was conducted to study the efficacy and safety of switching from potent P2Y ${ }_{12}$ inhibitors to clopidogrel, because there is no definite conclusion on the strategy.

Method: We conducted a systematic review and meta-analysis of patients with acute coronary syndromes (ACS) undergoing percutaneous coronary intervention, and compared the efficacy and safety of de-escalation or not of anti-platelet therapy. The relevant randomized controlled trials were included by searching several databases. Net adverse clinical events were identified as the composite endpoint, which was defined as a composite of cardiovascular death, myocardial infarction, revascularization, stroke and bleeding at 12 months after ACS. The efficacy endpoints were cardiovascular death, myocardial infarction, revascularization, stroke, all-cause death and stent thrombosis. Bleeding was designed as the safety endpoint. The relative risk (RR) and $95 \%$ confidence intervals $(\mathrm{Cl})$ of endpoint events were calculated by the fixed effects model.

Result: Six randomized controlled trials with 7627 patients met inclusion criteria. There were significant differences in the risk of net adverse clinical events (RR 0.67, $\mathrm{Cl} 0.58-0.78, P<0.00001)$, and bleeding endpoint $(0.61,0.52-0.71, P<0.00001)$ between the two groups. However, there were no significant differences in the risk of all efficacy endpoints.

Conclusions: The strategy of de-escalation from prasugrel/ticagrelor to clopidogrel can reduce the incidence of net adverse clinical events and bleeding events in patients with ACS undergoing percutaneous coronary intervention (Registered by PROSPERO at July 04 2021, ID 265782).

\section{Introduction}

Clopidogrel, prasugrel and ticagrelor are the most commonly used oral platelet $\mathrm{P} 2 \mathrm{Y}_{12}$ inhibitors. The latter is the second-generation thienopyridine. Given the potent evidence supporting the efficacy, safety, and cost-effectiveness of clopidogrel in the antiplatelet therapy, the strategy combining aspirin and clopidogrel as dual anti-platelet therapy is widely used in patients with acute coronary syndromes (ACS) undergoing percutaneous coronary intervention (PCI) [1]. However, a considerable number of patients have induced a poor antiplatelet effect of clopidogrel, which was initially defined as "clopidogrel resistant" [2] Enhanced platelet reactivity, increased platelet turnover and genetic polymorphisms may be the reasons for this phenomenon. Among them, genetic polymorphism is considered to be the most important determinants [3]. Studies have pointed out that the polymorphism of cytochrome P450 enzyme genes (such as CYP2C19) limits the effectiveness of clopidogrel [4], while prasugrel and ticagrelor are not affected [3, 5]. In addition, prasugrel and ticagrelor significantly reduced the incidence of ischemic events because of their more intensive effect of antiplatelet aggregation, but both agents increased risk of bleeding at the same time [6, 7]. The 2018 ESC/EACTS on myocardial revascularization recommend the use of prasugrel and ticagrelor instead of clopidogrel [8].

With the development of ACS therapy, the risk of bleeding gradually increases and the risk of ischemic events gradually decreases, which suggests that the deescalation of antiplatelet therapy may be possible [9]. The definition of de-escalation refers to any treatment that reduces the intensity of antiplatelet therapy and switching from a more intensive to a less intensive $\mathrm{P}_{2} \mathrm{Y}_{12}$ inhibitor, that is, from ticagrelor or prasugrel to clopidogrel, which defined as a modality of deescalation [10]. Therefore, this strategy of de-escalation is recommended as Class Ilb in the European Society of Cardiology guidelines for revascularization in 2018 and management of patients with non-ST elevation myocardial infarction in $2020[8,11]$.

Some meta-analyses have studied the efficacy of switching potent $\mathrm{P}_{2} \mathrm{Y}_{12}$ inhibitors to clopidogrel, but have not completely proved the superiority of deescalation of antiplatelet therapy compared with maintaining the original drugs in ACS patients undergoing PCI [12, 13]. In addition, these meta-analyses include both randomized controlled trials and observational studies, which may result in significant bias. The TALOS-AMI trial is the first large-scale randomized clinical trial to explore the efficacy and safety of de-escalation of antiplatelet therapy [14]. The results of the trial recently published at the American College of Cardiology conference showed that patients with acute myocardial infarction receiving de-escalation of anti-platelet therapy had a significantly lower risk of bleeding, but did not increase the risk of ischemia [15].

Therefore, we designed this systematic review and meta-analysis, including only randomized controlled trials, to verify the efficacy of switching potent P2Y 12 inhibitors to clopidogrel in ACS patients undergoing $\mathrm{PCl}$ compared with standard potent anti-platelet therapy. The results show that switching drugs can not only reduce the risk of clinical events, but also significantly reduce the incidence of bleeding events.

\section{Methods}

\section{Data Source and Quality Assessment}

The literature was searched by PubMed, Cochrane Library and Web of Science databases and 2021 American College of Cardiology Conference from inception to 1, July 2021. The meta-analysis only included randomized controlled trials compared efficacy and safety of de-escalation and non-de-escalation of anti-platelet therapy in ACS patients undergoing PCI. The key words were as follows: "prasugrel", "ticagrelor", "clopidogrel", "de-escalation", "switch", "acute coronary syndrome", "percutaneous coronary intervention" and "randomized controlled trials" (Supplementary Table 1-3). There were no language and year of publication restrictions. An update reminder for PubMed was created to keep up with the latest research. The inclusion criterion of the study met the following requirements: (1) patients with ACS without age limit; (2) patients received de-escalation therapy from prasugrel/ticagrelor to clopidogrel or continued original $\mathrm{P}_{2} \mathrm{Y}_{12}$ inhibitions; (3) trials reported the clinical endpoints of ischemic/bleeding events; (4) randomized controlled trials. The exclusion criterion of the study included: (1) duplicate reports; (2) meta-analyses, reviews, or comments; (3) reducing the dose of prasugrel and ticagrelor to de-escalate; (4) trials with incomplete data of outcomes. The title, abstract, and full text were independently read to ascertain the trials met the inclusion and exclusion criteria by two investigators (Bai N and Niu Y). The divergences were solved by consultation with the third party (Ma Y, Shang YS, and Zhong PY). The quality of each

Page 2/11 
randomized controlled trial was evaluated according to the Cochrane tool of Collaboration for assessing the risk of bias, and the quality of each outcome was evaluated by the Grades of Recommendations Assessment, Development and Evaluation (GRADE) [16, 17]. Ethical approval and patient consent are not required in this meta-analysis because the trials included are all published previously. The meta-analysis protocol was registered in PROSPERO (ID 265782).

\section{Data Acquisition And Clinical Endpoint}

Data extraction and analysis was performed according to the Preferred Reporting Items for Systematic Reviews and Meta-analysis (PRISMA) statement [18], and intention-to-treat analysis was employed. The baseline characteristics of patients and trials were extracted by two investigators independently, and the discrepancies were resolved through principal investigator (Wang ZL). The net adverse clinical events were identified as the composite endpoint, which was defined as a composite of cardiovascular death, myocardial infarction, revascularization, stroke and bleeding at 12 months after ACS. The efficacy endpoints were cardiovascular death, myocardial infarction, revascularization, stroke, all-cause death and stent thrombosis. The safety endpoint was bleeding as defined by the Bleeding Academic Research Consortium (BARC) criteria or the Thrombosis In Myocardial Infarction (TIMI) criteria in the studies included [19, 20]. However, each trial included had different design and bleeding grading criteria for reporting data. Therefore, the number of bleeding events included in the composite endpoint is different from the number of bleeding endpoint.

\section{Statistical Analysis}

This meta-analysis was used by Review Manager Version 5.4 software (The Nordic Cochrane Center, Copenhagen, Denmark), and the Cochrane Q statistic with Pearson chi-square test and the Higgins $I^{2}$ test were applied to assess heterogeneity in Review manager. If there was substantial heterogeneity $\left(I^{2} \geq\right.$ $50 \%$ ), the sensitivity analysis cannot be reduced, the random effect model was used. Otherwise, the risk ratio (RR) and $95 \%$ confidence interval (Cl) of each endpoint was calculated by the fixed effect model. In addition, the sensitivity analysis was employed to check the effect of any single study result on the overall results. The subgroup analysis was performed according to antiplatelet strategy, ACS performance, race and the timing of de-escalation. Two-tailed $P$ values were used for all results, and the statistical significance set at $P<0.05$. Trial Sequential Analysis (TSA) version 0.9.5.10 software was exploited to estimate the sample size of statistical differences of each outcome (based on an a of 0.05 and a power of 0.8 ). If less than ten studies were included, a publication bias was not analyzed.

\section{Results}

\section{Search Results and Study Characteristics}

The initial search yielded 12068 studies, majority of which reported on unrelated topics (Figure 1). Aggregated study-level data were finally obtained from 6 studies [15, 21-25], which included a total of 7627 patients met the inclusion criteria. Among them, 4609 (60.4\%) patients presented as ST elevation myocardial infarction, 2887 (37.9\%) as unstable angina/non-ST elevation myocardial infarction, 62 (0.8\%) as bundle-branch block and 69 (0.9\%) as non-ACS. The latter data were not used in this meta-analysis. The characteristics and endpoints of trials included are shown (Table 1 and 2 ). All patients included were adults (>18 years old). Majority of patients in the trials were male with an average age varying from 58.5 to 69.3 years. Aspirin was used as one of the basic drugs for dual anti-platelet therapy in all trials. Of the six dual anti-platelet therapy strategies, two trials evaluated the strategies from prasugrel and ticagrelor to clopidogrel [21, 23], two studies were devoted to switch from prasugrel to clopidogrel [24, 25], and another two studies of dual anti-platelet strategies were from ticagrelor to clopidogrel $[15,22]$. The switching time of four trails was less than one month [22-25] and that of two studies was at 30 days after randomization [15, 21]. The de-escalation strategy of one study was performed by platelet function testing-guided [24]. The baseline clinical and procedural characteristics of the included trials are depicted (Table 3). Multi-vessel disease was defined as the number of vessel with obvious stenosis or occlusion of more than one vessel. 
Table 1

Characteristics of the trials included.

\begin{tabular}{|c|c|c|c|c|c|c|c|c|c|c|c|}
\hline Study & Name & Journal & $\begin{array}{l}\text { Publication } \\
\text { year }\end{array}$ & $\begin{array}{l}\text { Multi- } \\
\text { center }\end{array}$ & Race & $\begin{array}{l}\text { No.of } \\
\text { patients }\end{array}$ & Randomization & $\begin{array}{l}\text { Types } \\
\text { of } \\
\text { stent }\end{array}$ & $\begin{array}{l}\text { P2Y12 } \\
\text { inhibition }\end{array}$ & $\begin{array}{l}\text { LD of } \\
\text { clopidogrel }\end{array}$ & $\begin{array}{l}\text { Timing } \\
\text { de- } \\
\text { escalat }\end{array}$ \\
\hline \multirow{3}{*}{$\begin{array}{l}\text { Cuisset } \\
\text { et al. [21] }\end{array}$} & \multirow[t]{3}{*}{ TOPIC } & \multirow[t]{3}{*}{ Eur Heart J } & \multirow[t]{3}{*}{2017} & \multirow[t]{3}{*}{ no } & \multirow[t]{3}{*}{ White } & \multirow[t]{3}{*}{646} & \multirow{3}{*}{$\begin{array}{l}\text { de-escalation } \\
(n=323) \text { vs. } \\
\text { placebo } \\
(n=323)\end{array}$} & DES & \multirow[t]{3}{*}{$P \& T$} & \multirow[t]{3}{*}{ no } & \multirow[t]{3}{*}{1 montl } \\
\hline & & & & & & & & BVS & & & \\
\hline & & & & & & & & BMS & & & \\
\hline $\begin{array}{l}\text { Li et al. } \\
\text { [22] }\end{array}$ & / & Clin Cardiol & 2018 & no & Yellow & 313 & $\begin{array}{l}\text { de-escalation } \\
(n=152) \text { vs. } \\
\text { placebo } \\
(n=161)\end{array}$ & DES & $\mathrm{T}$ & $44.7 \%$ & After PC \\
\hline \multirow{2}{*}{$\begin{array}{l}\text { Motovska } \\
\text { et al. [23] }\end{array}$} & PRAGUE- & \multirow{2}{*}{$\begin{array}{l}\text { J Am Coll } \\
\text { Cardiol }\end{array}$} & \multirow[t]{2}{*}{2018} & \multirow[t]{2}{*}{ yes } & \multirow[t]{2}{*}{ White } & \multirow[t]{2}{*}{1230} & \multirow{2}{*}{$\begin{array}{l}\text { de-escalation } \\
(n=481) \text { vs. } \\
\text { placebo } \\
(n=749)\end{array}$} & \multirow[t]{2}{*}{ / } & \multirow[t]{2}{*}{$P \& T$} & \multirow[t]{2}{*}{ no } & \multirow[t]{2}{*}{8 days } \\
\hline & 18 & & & & & & & & & & \\
\hline \multirow{2}{*}{$\begin{array}{l}\text { Park } \\
\text { et al. [15] }\end{array}$} & TALOS- & \multirow[t]{2}{*}{ Eurolntervention } & \multirow[t]{2}{*}{2021} & \multirow[t]{2}{*}{ yes } & \multirow[t]{2}{*}{ Yellow } & \multirow[t]{2}{*}{2697} & \multirow{2}{*}{$\begin{array}{l}\text { de-escalation } \\
(n=1349) \text { vs. } \\
\text { placebo } \\
(n=1348)\end{array}$} & \multirow[t]{2}{*}{ I } & \multirow[t]{2}{*}{$\mathrm{T}$} & \multirow[t]{2}{*}{ no } & \multirow[t]{2}{*}{1 montl } \\
\hline & AMI & & & & & & & & & & \\
\hline \multirow{3}{*}{$\begin{array}{l}\text { Sibbing } \\
\text { et al. }{ }^{[24]}\end{array}$} & \multirow{3}{*}{$\begin{array}{l}\text { TROPICAL- } \\
\text { ACS }\end{array}$} & \multirow[t]{3}{*}{ Lancet } & \multirow[t]{3}{*}{2017} & yes & White & 2610 & de-escalation & DES & $\mathrm{P}$ & no & After $\mathrm{PC}$ \\
\hline & & & & & & & placebo & BVS & & & \\
\hline & & & & & & & & BMS & & & \\
\hline $\begin{array}{l}\text { Ueno } \\
\text { et al. [25] }\end{array}$ & / & $\begin{array}{l}\text { Cardiovasc } \\
\text { Interv and Ther }\end{array}$ & 2017 & yes & Yellow & 131 & $\begin{array}{l}\text { de-cscalation } \\
(n=65) \text { vs. } \\
\text { placebo }(n=66)\end{array}$ & / & $\mathrm{P}$ & no & 1 week \\
\hline
\end{tabular}

Abbreviations: LD: loading dose; DES: drug-eluting stent; BVS: bioresorbable vascular scaffold; BMS: bare metal stent; P: prasugrel; T: ticagrelor; PCI: percutar coronary intervention

Table 2

Endpoints of the trials included.

\begin{tabular}{|c|c|c|c|}
\hline Author & The primary outcomes & The secondary outcomes & The safety outcomes \\
\hline $\begin{array}{l}\text { Cuisset et al. } \\
\text { [21] }\end{array}$ & $\begin{array}{l}\text { composite of CV death, urgent revascularization, stroke, } \\
\text { and bleeding }\end{array}$ & / & bleeding events and ST \\
\hline Li et al. [22] & MACE (CV death, nonfatal MI) and nonfatal ischemic stroke & $\begin{array}{l}\text { rehospitalization for angina, } \\
\text { revascularization, ST }\end{array}$ & bleeding events \\
\hline $\begin{array}{l}\text { Motovska et al. } \\
\text { [23] }\end{array}$ & composite of CV death, nonfatal MI or stroke & $\begin{array}{l}\text { composite of CV/all-cause death, MI, } \\
\text { stroke, ST }\end{array}$ & bleeding events \\
\hline Park et al. ${ }^{[15]}$ & $\begin{array}{l}\text { composite of CV death, MI, stroke, and BARC bleeding type } \\
2,3 \text { or } 5\end{array}$ & composite of CV death, MI or stroke & $\begin{array}{l}\text { BARC bleeding type } 2,3 \\
\text { or } 5\end{array}$ \\
\hline $\begin{array}{l}\text { Sibbing et al. } \\
\text { [24] }\end{array}$ & $\begin{array}{l}\text { composite of CV death, MI, stroke, and bleeding grade } 2 \text { or } \\
\text { higher }\end{array}$ & BARC bleeding 2 or higher at 12 months & BARC bleeding types $1-5$ \\
\hline Ueno et al. [25] & PRU at week 6 & / & $\begin{array}{l}\text { hemorrhagic events at } \\
\text { week } 6\end{array}$ \\
\hline
\end{tabular}


Table 3

Baseline clinical and procedural characteristics of patients included.

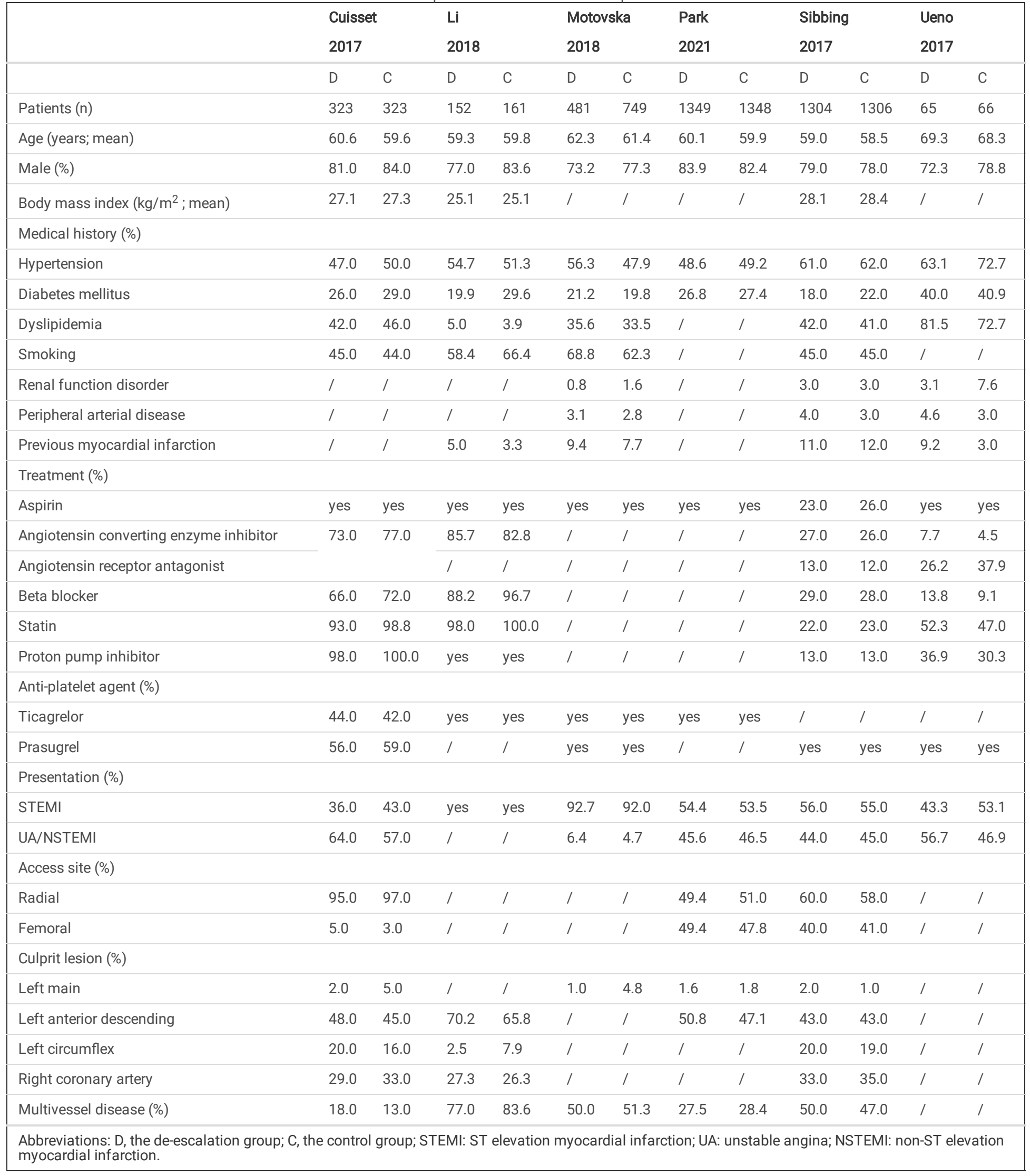

\section{Quality Assessment}

All studies in this meta-analysis were randomized controlled trials, and the risk of bias for each trial was assessed. The results of quality assessment are presented (Supplementary Figure 1). The risk of bias in selection, detection, attrition, reporting and other was low in all trials, but the risk of bias for 
performance was high in five of six trials, because these five trials were designed with open-label [15, 21, 23-25]. The evidence quality of each endpoint is evaluated (Supplementary Table 4). The quality of evidence was moderate for the endpoints of cardiovascular death, MI, stroke, all-cause death and stent thrombosis, and low for the composite endpoint, revascularizaiton and bleeding. The TSA of each endpoint is conducted (Supplementary Figure 2). The curve of the composite endpoint reached both the conventional boundary and TSA boundary, while that of the bleeding endpoint exceeded the expected sample size. The curve of cardiovascular death, MI and stroke did not meet either the conventional boundary or TSA boundary. The boundary TSA of revascularization, all-cause death and stent thrombosis was ignored due to too little information was used, which means that larger sample trials are needed to prove the results of these endpoints. No publication bias analysis was performed because less than 10 trails were included.

\section{The Composite Endpoint And Sensitivity Analysis}

The risk of the composite endpoint at 12-month is presented in three trials (Figure 2) [15, 21, 24], and the results showed that there were significant difference and moderate heterogeneity between the de-escalation and non-de-escalation of anti-platelet therapy groups $(8.2 \%$ vs $12.2 \%, \mathrm{RR} 0.67,0.58-0.78, P<0.00001$, and $\left.P^{2}=73 \%, P_{\text {Heterogeneity }}=0.02\right)$. Through sensitivity analysis, the heterogeneity is not observed after excluding the results of the trial by sibbing et al. $(R=$

$\left.0 \%, P_{\text {Heterogeneity }}=0.62\right)[24]$, and there is still significant difference between the two groups $(6.1 \%$ vs $11.3 \%$, RR $0.54,0.43-0.68, P<0.00001)($ Supplementary Figure 3A).

\section{The Efficacy Endpoints And Sensitivity Analysis}

The incidence of cardiovascular death, stroke and revascularization events was reported in four trials $[15,21,22,24]$. The incidence of cardiovascular death $\left(0.5 \%\right.$ vs $0.7 \%$, RR $0.69,0.36-1.32, P=0.26$, and $\left.P=0 \%, P_{\text {Heterogeneity }}=0.65\right)$ and stroke events $(0.4 \%$ vs $0.8 \%$, RR $0.59,0.30-1.13, P=0.11$, and $P=0 \%, P$ Heterogeneity $=0.86)$ is lower, while the risk of revascularization event is higher $(3.8 \%$ vs $3.3 \%, \mathrm{RR} 1.16,0.90-1.51, P=0.25$, and $P=71 \%, P$ Heterogeneity $=0.02)$ in the de-escalation group than those in the non-de-escalation group (Figure 3A-3C). The heterogeneity is reduced to mild (3.4\% vs $3.3 \%, \mathrm{RR} 1.02,0.78-1.34, P=$ 0.88 , and $I^{2}=22 \%, P_{\text {Heterogeneity }}=0.28$ ) by excluding one trial in the endpoint of revascularization [22] (Supplementary Figure 3B). However, there was no statistical difference and heterogeneity among three endpoints. In addition, three trials mentioned the endpoint of MI [15, 22, 24], and there is no significant difference between the two groups (1.4\% vs $1.7 \%$, RR $0.82,0.54-1.24, P=0.34$, and $\left.P=31 \%, P_{\text {Heterogeneity }}=0.23\right)$ (Figure 3D).

Meanwhile, two $[15,24]$ and four trials $[15,21,22,24]$ reports the incidence of all-cause death $(0.8 \%$ vs $0.8 \%, \mathrm{RR} 1.00,0.56-1.80, P=1.00$, and $P=0 \%, P$ Heterogeneity $=0.76)$ and stent thrombosis $\left(0.3 \%\right.$ vs $0.3 \%$, RR $1.00,0.40-2.51, P=1.00$, and $P=0 \%$, $\left.P_{\text {Heterogeneity }}=0.84\right)$, respectively (Figure $\left.3 \mathrm{E}, 3 \mathrm{~F}\right)$. The results demonstrated that the incidence of all-cause death and stent thrombosis were consistent between switching from potent $P 2 Y_{12}$ inhibitors to clopidogrel and maintaining original drug therapies.

\section{The Safety Endpoint And Sensitivity Analysis}

All trials reported the risk of bleeding $[15,21-25]$, and there are significant differences between the two strategies with moderate heterogeneity $(6.4 \%$ vs $10.7 \%$, RR $0.61,0.52-0.71, P<0.00001$, and $P=61 \%, P_{\text {Heterogeneity }}=0.02$ ) (Figure 4 ). The sensitivity analysis suggests that the statistical difference remained unchanged, and the heterogeneity was decreased by removing one trial $\left(5.1 \%\right.$ vs $10.8 \%$, RR $0.50,0.40-0.61, P<0.00001$, and $P^{2}=0 \%, P$ Heterogeneity $\left.=0.71\right)[24]$ (Supplementary Figure 3C).

\section{The Subgroup Analyses}

The subgroup analyses were performed according to predesign, but no significant differences are found from the composite endpoint in all subgroups (Supplementary Figure 4A-4D).

\section{Discussion}

The findings of this meta-analysis show that switching from potent $\mathrm{P}_{2} \mathrm{Y}_{12}$ inhibitor to less potent antiplatelet agent had a lower risk of composite endpoint of ischemic and bleeding events, and bleeding events, respectively in ACS patients undergoing PCI. In addition, the incidence of cardiovascular death, $\mathrm{MI}$ and stroke is also decreased, while the risk of revascularizaiton is increased, the incidence of all-cause death and stent thrombosis remained unchanged. However, significant differences are not observed in the above efficacy endpoints. The GRADE evidence level of safety and efficacy endpoints ranges from low to moderate according to the certainty of the evidence.

All trials in this meta-analysis were randomized controlled trials. The results showed that there was a low risk of bias in selection, detection, attrition, reporting and other bias, while there was a high risk of bias in performance owing to the lack of double-blinded design of trial. According to the results of this study, the risk of the composite endpoint and bleeding endpoint in the de-escalation group was lower than that in the non-de-escalation group. Among different subgroups, there was no significant difference in the risk of composite endpoint. In addition, the curve of the composite endpoint exceeded both the conventional boundary and TSA boundary, demonstrating that switching from potent $\mathrm{P}_{2} \mathrm{Y}_{12}$ inhibitor to less potent agent can reduce the risk of composite of cardiovascular death, $\mathrm{MI}$, stroke, revascularization and bleeding in ACS patients undergoing PCI. The conclusion should be considered as a real positive trial 
without more randomized controlled trials. Finally, this study searched PubMed, Cochrane Library and Web of science databases without language limitation, and the selection and inclusion of meta-analysis can be repeated.

The meta-analysis showed that the relative risk of composite endpoint was reduced by $33 \%$ at 12 months in ACS patients undergoing PCl, with significant difference, but moderate heterogeneity was observed. After removing the results of TROPICAL-ACS trial [24], the risk ratio of de-escalation group was almost half that of the non-de-escalation group. Meanwhile, the heterogeneity was reduced to zero, and there were still significant differences. The TSA curve of the composite endpoint exceeded both the conventional boundary and TSA boundary when heterogeneity was moderate, and it also met these two boundaries when there was no heterogeneity, indicating that positive effect of de-escalation in the composite endpoint of ischemic and bleeding did not need to be proved by larger trials.

The incidence of cardiovascular death, $\mathrm{Ml}$, and stroke in the de-escalation group was lower than that in the non-de-escalation group without significant difference, and the curves of these endpoints did not exceed sample size, which means larger scale trials are needed to support this conclusion. Another metaanalysis also yielded similar result [12]. It should be noted that the above trial included both randomized controlled trials and observational studies, which may lead to larger risk of bias. Regarding other efficacy endpoints, such as revascularization, stent thrombosis, and all-cause death, the risk ratio of these endpoints was not less than one. In addition, the boundary TSA is ignored in all of these endpoints due to the small number of reported events.

Higher risk of bleeding, regardless of major or minor bleeding, of ticagrelor and prasugrel was reported in some clinical trials and meta analyses [6, 7, 26, 27]. Based on this, it can be reasonably assumed that the risk of bleeding will be reduced after de-escalation. The results of this study are consistent with the hypothesis. However, the heterogeneity was moderate. The trial by Sibbing et al. is considered to be the main cause of heterogeneity by further sensitivity analysis [24]. In this trial, the risk of bleeding in the de-escalation group was not significantly lower than that in the non-de-escalation group. This may be related to the fact that $40 \%$ of patients in the de-escalation group required to be upgraded back to prasugrel, which increased the risk of bleeding. After excluding the trial, the risk ratio of bleeding in the de-escalation was reduced by half and remained statistically significant. In addition, the curve of bleeding endpoint exceeded the conventional boundary and TSA boundary, indicating a probability of false-positive result of $<5 \%$. Therefore, no more randomized controlled trials are needed to support the result. Moreover, in four other trials included [15, 21-23], the incidence of bleeding events doubled in the non-deescalation group. Although the incidence of bleeding was similar between the two groups in the trial by Ueno et al. [25], the sample size of patients in this trial was small, which led to small weight of statistics data. This may explain why it has no significant effect on the results.

The results of this meta-analysis need to be interpreted carefully. Firstly, the de-escalation of dual antiplatelet therapy based on platelet function testing or CYP2C19 genotype has been recommended by some guidelines $[8,11]$. Of the six trials included, the TROPICAL-ACS trial is the only one used platelet function testing to guide de-escalation of dual antiplatelet therapy. This makes it is impossible to perform subgroup analysis with or without guidance of platelet function testing or CYP2C19 genotype. According to the results of the TROPICAL-ACS trial, the net clinical benefit of guided de-escalation dual antiplatelet therapy under the platelet function testing was not inferior to standard therapy with prasugrel [24]. Another study showed that switching from prasugrel/ticagrel to clopidogrel seems to be safe and effective in patients without CYP2C19 nonfunctional allele under the guidance of genotype [28]. However, this issue deserves further study. Secondly, there was no difference in the endpoint of composite of ischemic and bleeding among the ethnic subgroups of this meta-analysis. In addition, Asian patients may have a higher risk of bleeding than the western population [29]. Finally, there was no difference between the de-escalation and non-de-escalation of dual antiplatelet therapy groups, whenever switching drugs at 1 month or within 1 month. At present, the recommendations on this subject are not clear, and further large sample trials are needed.

\section{Limitations}

The present meta-analysis of randomized clinical trials may have some limitations. First of all, there are inevitable differences between trials, such as criterion of bleeding classification, the design of the primary endpoints, and the definition of endpoints. Secondly, all trials included are non-double blinded design, which may affect the quality of the study because of the increased risk of bias. In addition, publication bias was not implemented because less than ten trials included. Thirdly, other subgroup analyses, such as gender, age, diabetes mellitus, left ventricular ejection fractions and glomerular filtration rate cannot be performed because not all trials included in this study reported relevant data for subgroups mentioned above. Finally, according to the results of TSA, the outcomes of cardiovascular death, MI and stroke did not surpass the traditional and TSA boundary, and the TSA boundaries of revascularization, stent thrombosis and all-cause death were ignored due to little information used, which may lead to false-positive results. Therefore, more randomized clinical trials are needed to further confirm the efficacy of the strategy.

\section{Conclusions}

This systematic review and meta-analysis demonstrates that switching from potent $\mathrm{P} 2 \mathrm{Y}_{12}$ inhibitors (prasugrel/ticagrel) to clopidogrel was associated with lower risk of bleeding and composite endpoint of ischemic and bleeding in ACS patients undergoing PCl. Regardless of ticagrelor or prasugrel, patients with or without ST elevation, yellow or white race, and switching drugs at one month or earlier, there was no significant difference between the de-escalation and nonde-escalation groups in the composite endpoint.

\section{Declarations}

\section{Funding}

The authors declare that no funds, grants, or other support were received during the preparation of this manuscript.

\section{Competing Interests}


The authors have no relevant financial or non-financial interests to disclose.

\section{Author contributions}

Nan Bai contributed to the study conception and design. Material preparation, data collection and analysis were performed by Nan Bai, Ying Niu, Ying Ma, Yaosheng Shang and Peng-yu Zhong. The first draft of the manuscript was written by Nan Bai and scientific revision of the manuscript was performed by Zhi-Lu Wang. All authors read and approved the final manuscript.

\section{Data availability}

Data sharing not applicable to this article as no datasets were generated or analyzed during the current study.

\section{References}

[1] Patti G, Micieli G, Cimminiello C, Bolognese L. The Role of Clopidogrel in 2020: A Reappraisal. Cardiovasc Ther. 2020: 8703627. doi: $10.1155 / 2020 / 8703627$.

[2] Angiolillo DJ, Fernandez-Ortiz A, Bernardo E et al. Variability in individual responsiveness to clopidogrel: clinical implications, management, and future perspectives. J Am Coll Cardiol. 2007; 10;49(14):1505-16. doi: 10.1016/j.jacc.2006.11.044.

[3] Campo G, Fileti L, Valgimigli M, et al. Poor response to clopidogrel: current and future options for its management. J Thromb Thrombolysis. 2010;30(3):319-31. doi: 10.1007/s11239-010-0457-5.

[4] Campo G, Valgimigli M, Gemmati D, et al. Poor responsiveness to clopidogrel: drug-specific or class-effect mechanism? Evidence from a clopidogrel-toticlopidine crossover study. J Am Coll Cardiol. 2007;50(12):1132-7. doi: 10.1016/j.jacc.2007.04.092.

[5] Storey RF, Husted S, Harrington RA, et al. Inhibition of platelet aggregation by AZD6140, a reversible oral P2Y12 receptor antagonist, compared with clopidogrel in patients with acute coronary syndromes. J Am Coll Cardiol. 2007;50(19):1852-6. doi: 10.1016/j.jacc.2007.07.058.

[6] Wallentin L, Becker RC, Budaj A, et al. Ticagrelor versus clopidogrel in patients with acute coronary syndromes. N Engl J Med. 2009;361(11):1045-57. doi囚 10.1056/NEJMoa0904327.

[7] Wiviott SD, Braunwald E, McCabe CH, et al. Prasugrel versus clopidogrel in patients with acute coronary syndromes. N Engl J Med. 2007;357(20):2001-15. doi囚10.1056/NEJMoa0706482.

[8] Sousa-Uva M, Neumann FJ, Ahlsson A, et al. 2018 ESC/EACTS Guidelines on myocardial revascularization. Eur J Cardiothorac Surg. 2019;55(1):4-90. doi: 10.1093/ejcts/ezy289.

[9] Rodriguez F, Harrington RA. Management of Antithrombotic Therapy after Acute Coronary Syndromes. N Engl J Med. 2021;384(5):452-460. doi: 10.1056/NEJMra1607714.

[10] Angiolillo DJ, Rollini F, Storey RF, et al. International Expert Consensus on Switching Platelet P2Y 12 Receptor-Inhibiting Therapies. Circulation. 2017;136(20):1955-1975. doi: 10.1161/CIRCULATIONAHA.117.031164.

[11] Barbato E, Mehilli J, Sibbing D, et al. Questions and answers on antithrombotic therapy and revascularization strategies in non-ST-elevation acute coronary syndrome (NSTE-ACS): a companion document of the 2020 ESC Guidelines for the management of acute coronary syndromes in patients presenting without persistent ST-segment elevation. Eur Heart J. 2021;42(14):1368-1378. doi: 10.1093/eurheartj/ehaa601.

[12] Angiolillo DJ, Patti G, Chan KT, et al. De-escalation from ticagrelor to clopidogrel in acute coronary syndrome patients: a systematic review and metaanalysis. J Thromb Thrombolysis. 2019;48(1):1-10. doi: 10.1007/s11239-019-01860-7.

[13] Guo C, Li M, Lv YH, Zhang MB, Wang ZL. De-escalation versus standard dual antiplatelet therapy in patients undergoing percutaneous coronary intervention: a systematic review and meta-analysis. Platelets. 2020;31(1):15-25. doi: 10.1080/09537104.2019.1574969.

[14] Park MW, Kim CJ, Kim MC, et al. A prospective, multicentre, randomised, open-label trial to compare the efficacy and safety of clopidogrel versus ticagrelor in stabilised patients with acute myocardial infarction after percutaneous coronary intervention: rationale and design of the TALOS-AMI trial. Eurolntervention. 2021;16(14):1170-1176. doi: 10.4244/EIJ-D-20-00187.

[15] ACC.21 Presentation Slides, TALOS-AMI. In: Ticagrelor vs. Clopidogrel in Stabilized Patients after AMI. 2021. https://www.acc.org/education-andmeetings/image-and-slide-gallery/media-detail?id=70A25401C38D41049E72B92187AB6ECD. Accessed May 16,2021.

[16] Higgins JP, Altman DG, Gotzsche PC, et al. The Cochrane collaboration's tool for assessing risk of bias in randomised trials. BMJ (Clinical Research Ed) 2011; 343: d5928. doi:10.1136/ bmj.d5928.

[17] Guyatt GH, Oxman AD, Vist GE, et al. GRADE: an emerging consensus on rating quality of evidence and strength of recommendations. BMJ (Clinical Research Ed) 2008; 336: 924-926. doi:10.1136/bmj.39489.470347.AD. 
[18] Liberati A, Altman DG, Tetzlaff J, et al. The PRISMA statement for reporting systematic reviews and meta-analyses of studies that evaluate healthcare interventions: explanation and elaboration. BMJ 2009; 339: b2700. doi:10.1136/bmj.b2700.

[19] Mehran R, Rao SV, Bhatt DL, et al. Standardized bleeding definitions for cardiovascular clinical trials: a consensus report from the Bleeding Academic Research Consortium. Circulation. 2011;123(23):2736-47. doi: 10.1161/CIRCULATIONAHA.

[20] Chesebro JH, Knatterud G, Roberts R, et al. Thrombolysis in myocardial infarction (TIMI) trial, phase l: a comparison between intravenous tissue plasminogen activator and intravenous streptokinase. Clinical findings through hospital discharge. Circulation 1987; 76:142-154. doiß 10.1161/01.CIR.76.1.142.

[21] Cuisset T, Deharo P, Quilici J, et al. Benefit of switching dual antiplatelet therapy after acute coronary syndrome: the TOPIC (timing of platelet inhibition after acute coronary syndrome) randomized study. Eur Heart J. 2017;38(41):3070-3078. doi: 10.1093/eurheartj/ehx175.

[22] Li XY, Su GH, Wang GX, Hu HY, Fan CJ. Switching from ticagrelor to clopidogrel in patients with ST-segment elevation myocardial infarction undergoing successful percutaneous coronary intervention in real-world China: Occurrences, reasons, and long-term clinical outcomes. Clin Cardiol. 2018;41(11):14461454. doi: $10.1002 /$ clc. 23074 .

[23] Motovska Z, Hlinomaz O, Kala P, et al. 1-Year Outcomes of Patients Undergoing Primary Angioplasty for Myocardial Infarction Treated With Prasugrel Versus Ticagrelor. J Am Coll Cardiol. 2018;71(4):371-381. doi: 10.1016/j.jacc.2017.11.008.

[24] Sibbing D, Aradi D, Jacobshagen C, et al. Guided de-escalation of antiplatelet treatment in patients with acute coronary syndrome undergoing percutaneous coronary intervention (TROPICAL-ACS): a randomised, open-label, multicentre trial. Lancet. 2017; 390 (10104): 1747-1757. doi: 10.1016/S01406736(17)32155-4.

[25] Ueno T, Koiwaya $\mathrm{H}$, Sasaki KI, et al. Changes in P2Y12 reaction units after switching treatments from prasugrel to clopidogrel in Japanese patients with acute coronary syndrome followed by elective coronary stenting. Cardiovasc Interv Ther. 2017; 32(4): 341-350. doi: 10.1007/s12928-016-0417-x.

[26] Lee CH, Huang MS, Chao TH, Lin SH, Li YH. Reduced-Dose Prasugrel versus Clopidogrel for Patients Undergoing Percutaneous Coronary Intervention. Int Heart J. 2021;62(2):246-255. doi: 10.1536/ihj.20-508.

[27] Fan ZG, Zhang WL, Xu B, Ji J, Tian NL, He SH. Comparisons between ticagrelor and clopidogrel following percutaneous coronary intervention in patients with acute coronary syndrome: a comprehensive meta-analysis. Drug Des Devel Ther. 2019; 13: 719-730. doi: 10.2147/DDDT.S196535.

[28] Martin J, Williams AK, Klein MD, et al. Frequency and clinical outcomes of CYP2C19 genotype-guided escalation and de-escalation of antiplatelet therapy in a real-world clinical setting. Genet Med. 2020;22(1):160-169.

[29] Misumida N, Aoi S, Kim SM, Ziada KM, Abdel-Latif A. Ticagrelor versus clopidogrel in East Asian patients with acute coronary syndrome: Systematic review and meta-analysis. Cardiovasc Revasc Med. 2018;19(6):689-694. doi: 10.1016/j.carrev.2018.01.009.

\section{Figures}




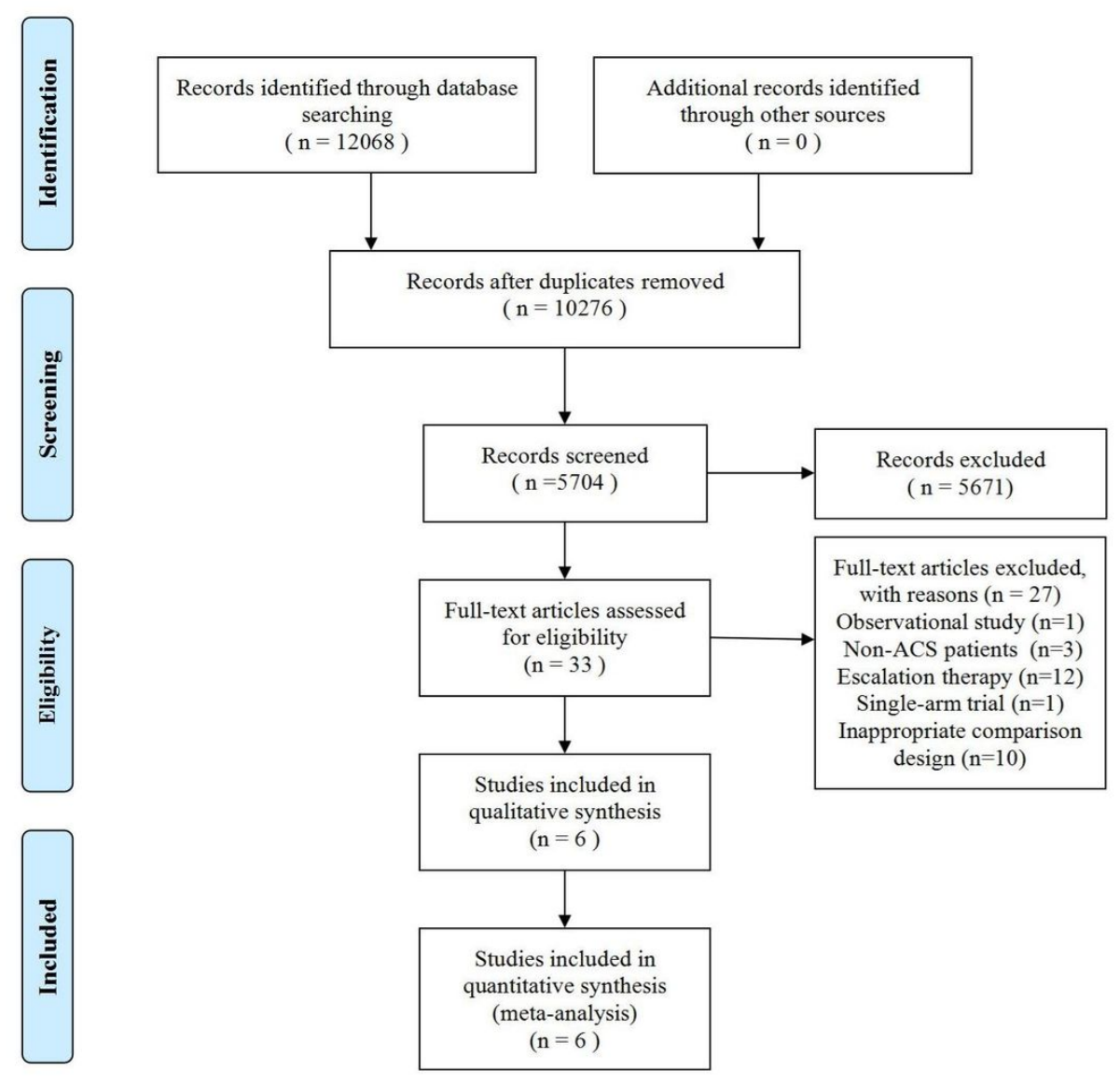

\section{Figure 1}

Flow diagram of literature search

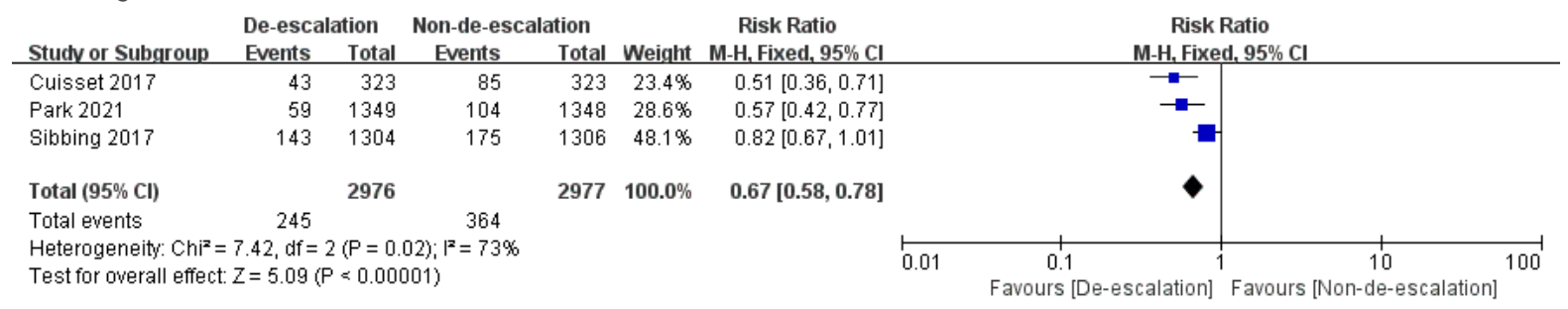

\section{Figure 2}

Comparison of the composite endpoint between the de-escalation and non- de-escalation of anti-platelet therapy groups 


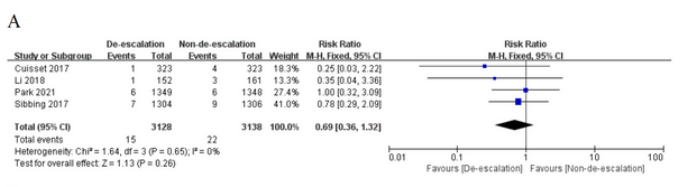

B

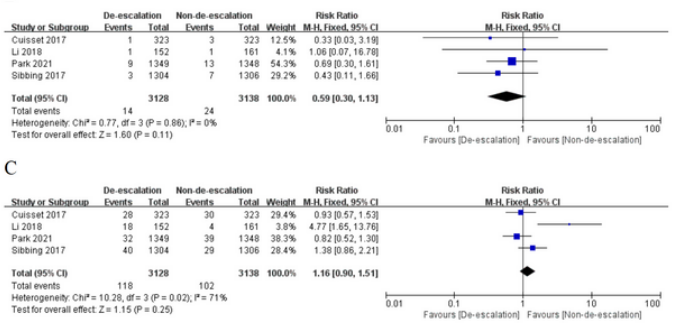

D

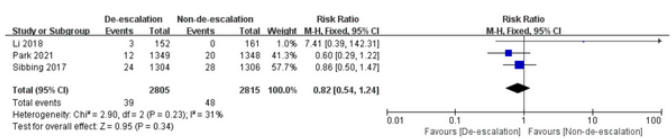

$\mathrm{E}$

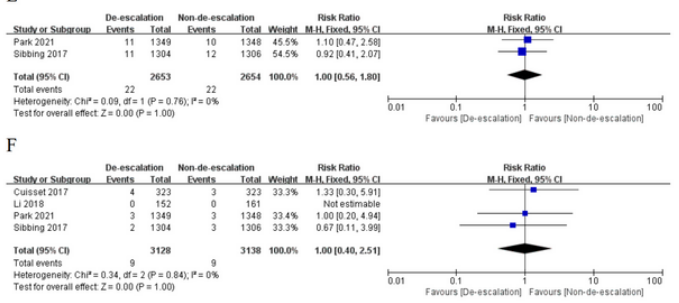

\section{Figure 3}

Comparison of the efficacy endpoints between the de-escalation and non- de-escalation of anti-platelet therapy groups. (A) cardiovascular death, (B) stroke, (C) revascularization, (D) myocardial infarction, (E) all-cause death, (F) stent thrombosis

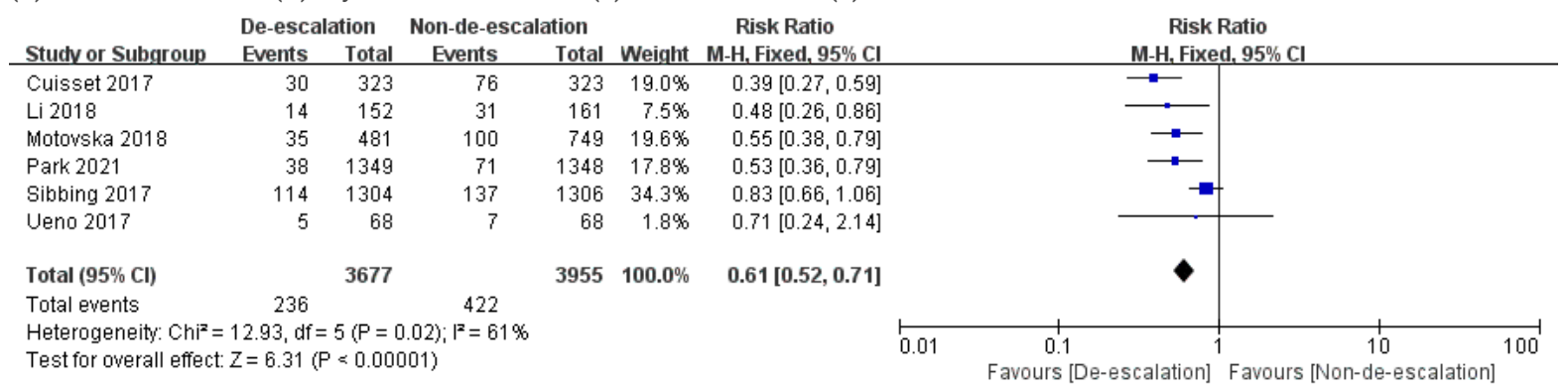

\section{Figure 4}

Comparison of the safety endpoint between the de-escalation and non-de-escalation of anti-platelet therapy groups

\section{Supplementary Files}

This is a list of supplementary files associated with this preprint. Click to download.

- SupplementaryInformation.docx 